\title{
Erratum to: A Nebulized Gelatin Nanoparticle-Based CpG Formulation is Effective in Immunotherapy of Allergic Horses
}

John Klier • Sebastian Fuchs • Anna May • Ulrike Schillinger • Christian Plank • Gerhard Winter • Conrad Coester • Heidrun Gehlen

Published online: 1 May 2012

(C) Springer Science+Business Media, LLC 2012

\section{Erratum to: Pharm Res}

\section{DOI 10.1007/s11095-012-0686-8}

The order of authors should read as follows: John Klier, Sebastian Fuchs, Anna May, Ulrike Schillinger, Christian Plank, Gerhard Winter, Conrad Coester, Heidrun Gehlen.

\footnotetext{
The online version of the original article can be found at http://dx.doi.org/ | 0.1007/s | |095-0|2-0686-8.

J. Klier · A. May

Department of Veterinary Medicine, Equine Clinic

Ludwig Maximilians University

Munich, Germany

S. Fuchs $\cdot$ G. Winter $\cdot$ C. Coester $(\bowtie)$

Department of Pharmacy,

Pharmaceutical Technology and Biopharmacy

Ludwig Maximilians University

Butenandtstr. 5

81377 Munich, Germany

e-mail: conrad.coester@cup.uni-muenchen.de

U. Schillinger $\cdot C$. Plank

Institute of Experimental Oncology and Therapy Research

Technical University of Munich

Munich, Germany

H. Gehlen ( $\square)$

Department of Veterinary Medicine, Equine Clinic

Surgery and Radiology, Freie Universität Berlin

Oertzenweg 19b

14163 Berlin, Germany

e-mail: gehlen.heidrun@vetmed.fu-berlin.de 